\title{
El Museo Arqueológico Regional de la Comunidad de Madrid transforma en exposición casi 30 años de esfuerzo y trabajo paleontológicos
}

\author{
Los yacimientos del cerro de los Batallones (Torrejón de Velasco, Comunidad de Madrid) son una referencia \\ mundial en el campo de la paleontología del Mioceno. Tras casi treinta años de campañas de excavación \\ e innumerables estudios científicos y actividades de difusión, el Museo Arqueológico Regional de la \\ Comunidad de Madrid (MAR) ofrece al público una exposición que reúne las conclusiones de tantos años \\ de esfuerzo y trabajo concienzudo. La muestra, organizada en torno a cinco áreas temáticas, presenta \\ una lectura completa, amena y rigurosa de los yacimientos. Tanto la exposición como las publicaciones \\ editadas tienen una intención evidentemente divulgativa y formativa.
}

\begin{abstract}
María Carrillo Tundidor, Enrique Baquedano Pérez | respectivamente, responsable de exposiciones y director del Museo Arqueológico Regional de la Comunidad de Madrid

Jorge Morales Romero | comisario científico, Museo Nacional de Ciencias Naturales (CSIC)

URL de la contribución <www.iaph.es/revistaph/index.php/revistaph/article/view/4199>
\end{abstract}

Desde su descubrimiento fortuito en 1991, mientras se producían en la zona trabajos de extracción de minerales, los yacimientos situados en el cerro de los Batallones (Torrejón de Velasco, Comunidad de Madrid) despertaron el interés de la comunidad científica, que ha asistido expectante durante años a los continuos y sorprendentes hallazgos en las sucesivas campañas de excavación que se han realizado durante veintisiete años.

Las publicaciones científicas y la labor de difusión del proyecto de investigación liderado por uno de nosotros (Jorge Morales Romero) han sido una constante desde el principio, y así lo demuestran, entre otros muchos estudios científicos, las nueve tesis doctorales leídas en torno a los hallazgos de los yacimientos.

No obstante, tras veintisiete años de trabajo, el Museo Arqueológico Regional de la Comunidad de Madrid consideró que había llegado el momento de ofrecer al público una exposición que reuniera las conclusiones de tantos años de esfuerzo y de trabajo concienzudo, y que permitiera contemplar por primera vez los extraordinarios restos de un anónimo cerro que escondía la clave para entender el paisaje natural de la cuenca de Madrid de hace nueve millones de años. Esta exposición ofrecía al museo ade- más la posibilidad de demostrar la riqueza paleontológica del territorio, y que se ha puesto de manifiesto en las continuas obras públicas acometidas en los últimos años.

Los yacimientos del cerro de los Batallones son, efectivamente, una referencia mundial en el campo de la paleontología del Mioceno por diversas razones: la gran acumulación de restos óseos, su excelente conservación, destacando sobre todo la posición anatómica en la que se encuentran, la diversidad de la fauna (especialmente de carnívoros) y, obviamente, la antigüedad asignada al yacimiento, que se calcula en más de nueve millones de años. Representa además un caso de estudio en lo que se refiere a las condiciones geológicas del entorno, que han permitido no sólo la formación de los propios yacimientos, sino también su preservación. La importancia de los yacimientos fue avalada por la Comunidad de Madrid quien apoyó los trabajos de excavación desde los inicios y quien declaró el entorno bien de interés cultural en el año 2001, lo que supuso una medida definitiva para su protección.

El equipo encargado de diseñar los contenidos de la exposición ha tenido como objetivo prioritario ofrecer una lectura completa, amena y rigurosa de los yacimien- 


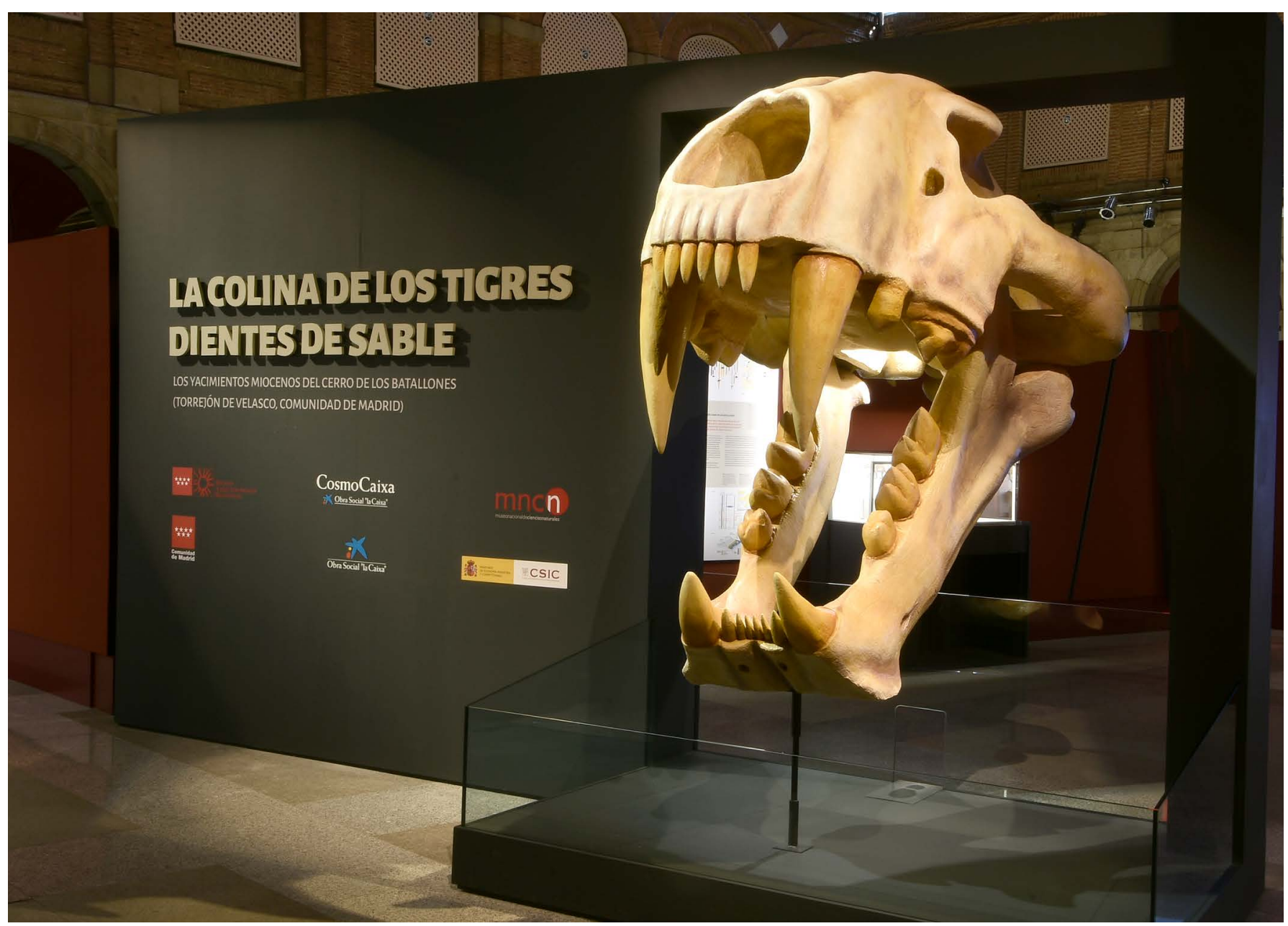

Entrada a la exposición | fotos Museo Arqueológico Regional (Mario Torquemada), titular de todas las imágenes que ilustran este texto, mientras no se indique lo contrario
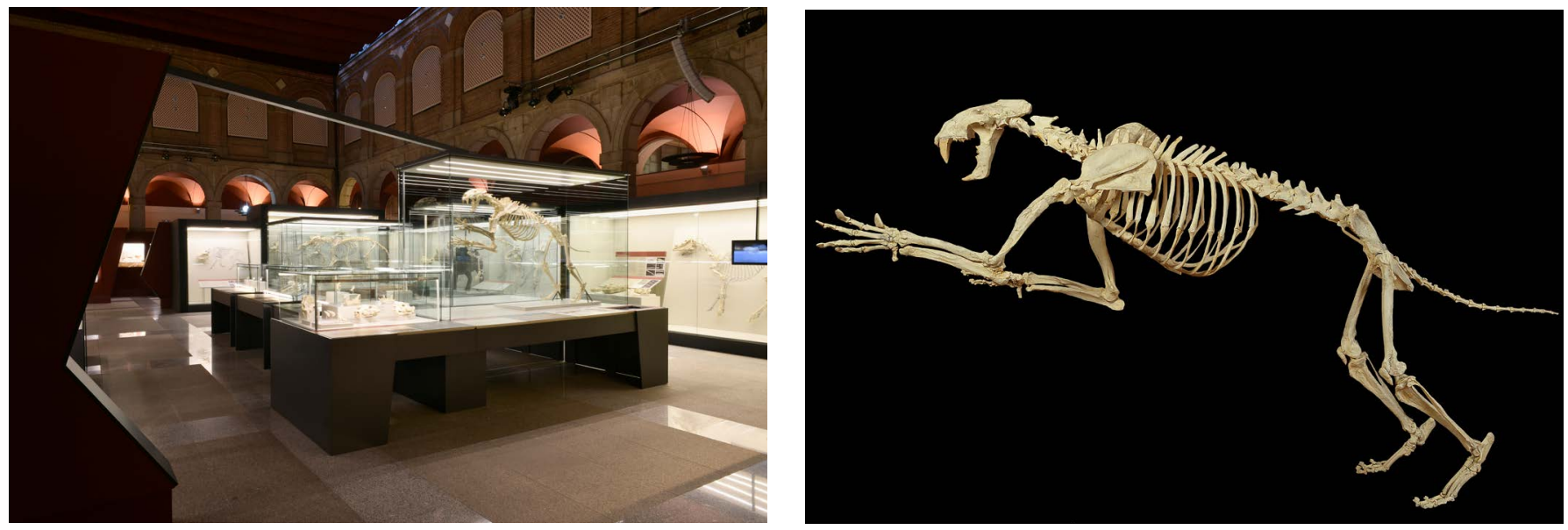

Sala central de la exposición

Reproducción del tigre dientes de sable Machairodus aphanistus 
tos, exponiendo no sólo una selección de los restos aparecidos, sino las conclusiones a las que se ha llegado a lo largo de los años de estudio. Para ello, se ha recurrido a herramientas expositivas que jerarquizan la información en diversos niveles de comprensión: paneles informativos, cartelas, audiovisuales, reconstrucciones en 3D e ilustraciones.

Las ilustraciones, realizadas por el ilustrador y artista paleontológico Mauricio Antón, ocupan un lugar destacado dentro de la exposición, no sólo por el formato de reproducción, en cajas retroiluminadas de 2,20 × 3,40 m, sino también por su vocación evocadora, al remitirnos a las reconstrucciones del ambiente natural en el que se formaron los yacimientos.

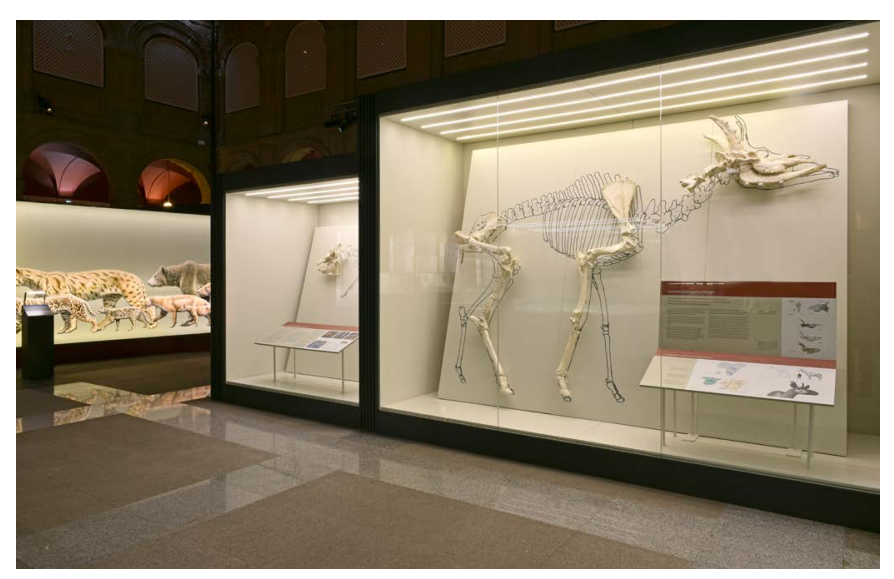

Montaje anatómico de Decennatherium rex

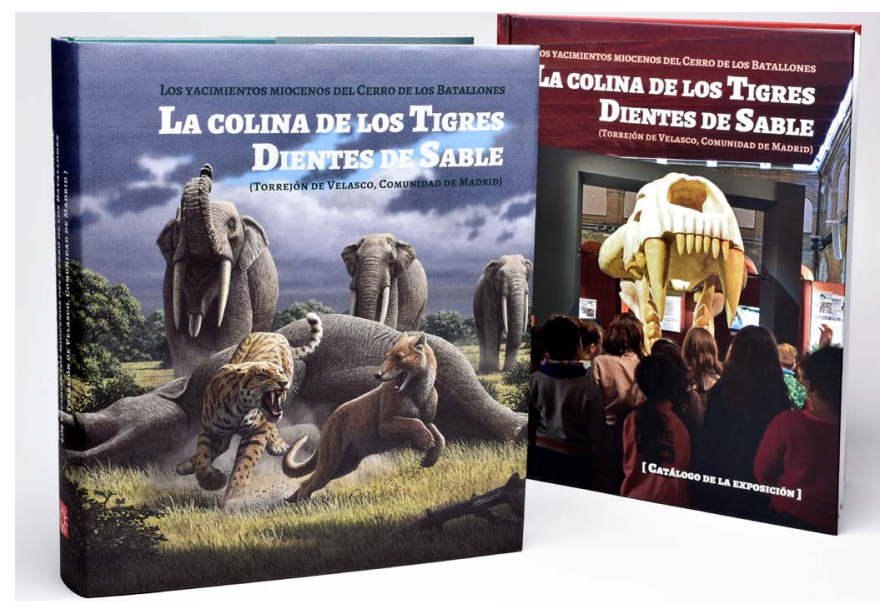

Publicaciones de la exposición
La información ofrecida al visitante se organiza en torno a cinco áreas temáticas: en la introducción se presenta, junto a un video de tres minutos de duración, la historia del descubrimiento de los yacimientos, localizados durante las tareas de explotación minera de sepiolita en la zona. En esta área se presentan los primeros restos encontrados, que dieron origen al inicio de las investigaciones y excavaciones científicas en la zona. A continuación, se analiza el contexto geológico de los yacimientos, poniéndolo en relación con otros yacimientos de la cuenca de Madrid. En la tercera área se trata el origen y formación de las cavidades que han dado lugar a los yacimientos. En esta área se muestran tres grandes ilustraciones retroiluminadas de Mauricio Antón que reconstruyen el ambiente ecológico de Madrid hace nueve millones de años y el interior de una de las cavidades, junto al fósil de una tortuga gigante (Titanochelon) y una gran acumulación de huesos en la que se aprecian los restos de dos individuos distintos, un antepasado de la jirafa (Decennatherium rex) y un caballo (Hipparion). Se incluye además un video con una duración de dos minutos y medio en el que se explica el proceso de formación y sedimentación de las cavidades que ha dado lugar a la excepcional concentración de fósiles que presentan los yacimientos del cerro de los Batallones.

La cuarta área de la exposición, dedicada a la fauna de cerro de los Batallones, es la que reúne la mayor parte de los fósiles presentes en la exposición: carnívoros, herbívoros, pequeños mamíferos, aves, peces... Se configura una gran isla central dedicada a los restos de carnívoros presidida por una reproducción a escala real de un tigre dientes de sable (Machairodus aphanistus), y rodeada de las vitrinas dedicadas a los herbívoros y al resto de animales. Los fósiles se presentan en posición anatómica sobre siluetas dibujadas, junto a animaciones en 3D que reconstruyen el movimiento y características de los animales.

La quinta y última sección de la exposición se denomina "Más allá de los fósiles", e introduce al visitante en los diferentes análisis e investigaciones que se realizan en torno al yacimiento a fin de recabar información sobre las condiciones ambientales en las que se desarrolló la vida hace nueve millones de años. En esta área se 


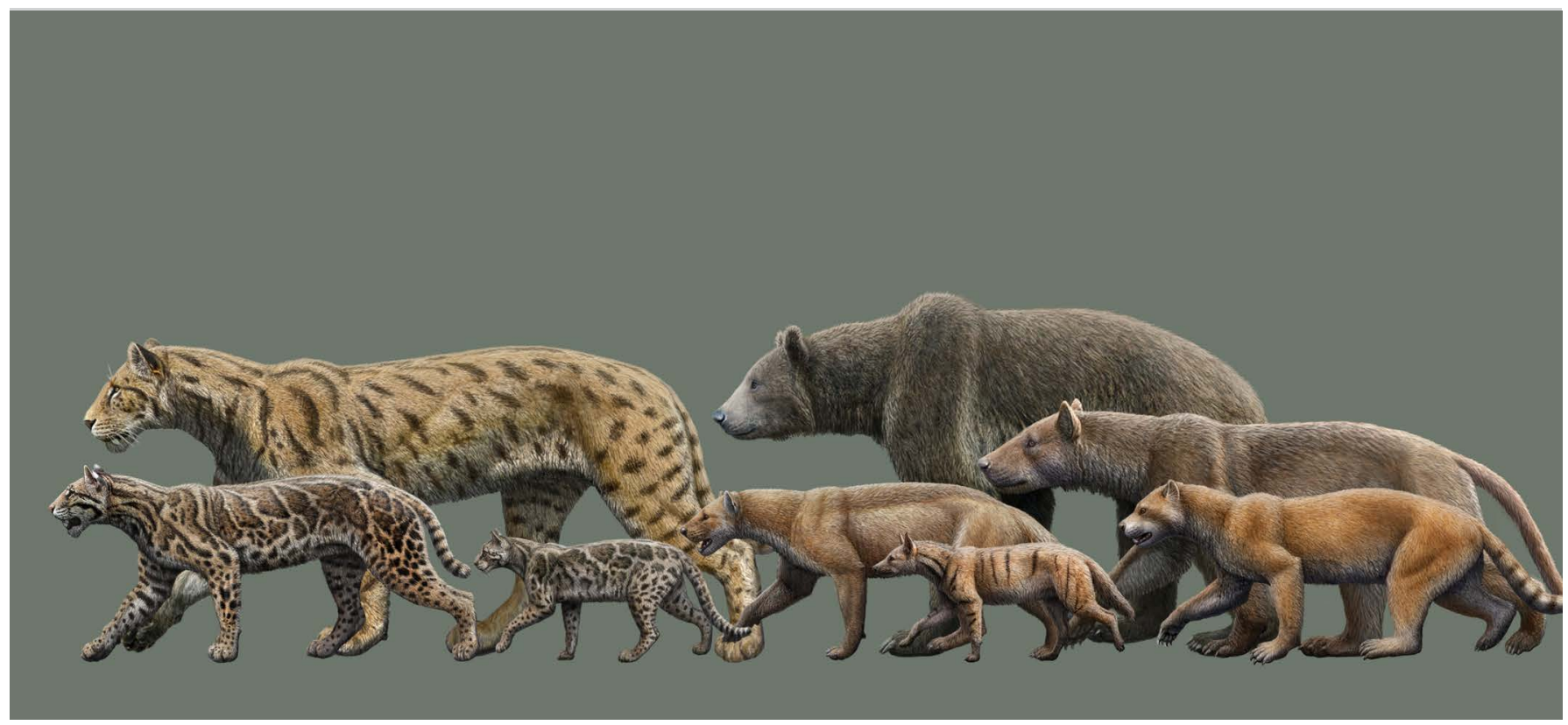

Ambiente ecológico de Madrid hace nueve millones de años | ilustración Mauricio Antón

incluye una pequeña sala de proyección con la película de 34 minutos de duración Devolviendo a la vida a los félidos dientes de sable, sobre las técnicas de reconstrucción de esqueletos, tejidos blandos, ambiente, vegetación, locomoción, caza, así como sobre las técnicas artísticas tradicionales y digitales.

La exposición tiene una evidente naturaleza comunicadora y formativa: trata de ofrecer un panorama lo más exacto posible, con toda fidelidad, de los descubrimientos científicos que nos aportan sus restos. Las publicaciones que se han editado con motivo de la exposición recogen esta misma voluntad, tratando de cubrir los diferentes públicos a los que se dirige. Para ello, se ha realizado una publicación de más de 600 páginas y más de cuarenta artículos redactados por los principales especialistas que han trabajado en el cerro de los Batallones desde su descubrimiento. Junto a esta publicación de carácter científico, se ha editado un catálogo que contiene todos los textos incluidos en los paneles y cartelas de la exposición, junto a las piezas (más de 160) que el visitantes puede contemplar a lo largo del recorrido.

Las actividades organizadas en torno a la exposición tratan de recoger el enorme impacto que está teniendo entre el público, y que avalan las cifras de visitantes, como talleres infantiles, visitas guiadas, una mesa redonda coincidiendo con La Noche de los Museos y conferencias el Día Internacional de los Museos, así como la participación activa en el Geolodía 18, en la que uno de los platos fuertes es la visita a la exposición.

La tienda del museo no ha sido ajena a la invasión faunística que esta exposición ha traído, mediante la incorporación de gran número de objetos con los principales motivos de la exposición: camisetas, tazas, cuadernos, delantales, postales, marca páginas...

Se trata, sin duda, de que todo el museo participe al unísono en el mensaje que se quiere transmitir mediante la organización de esta exposición: la difusión del rico patrimonio paleontológico de la Comunidad de Madrid y la excelente labor investigadora que se lleva a cabo en torno a él. 